are good, but the illustration of the preparation of a molar solution (page 276) is a demonstrator's nightmare. Misprints are rare $\left(\mathrm{XeF}_{3}\right.$ and $\mathrm{CaCl}$ for $\left.\mathrm{CsCl}\right)$, but the use of symbols like $\mathrm{Ca}^{+2}$ and ${ }_{17} \mathrm{Cl}_{35 \cdot 453}$ is unconventional. The attempt to follow "official" nomenclature is commendable but the authors stand firm in their use of oxidation potentials rather than the more favoured IUPAC system. Use of "main" and "transition" groups or $s, p$ and $d$ blocks would avoid the confusion caused by labelling transition metals as "B" groups.

While elements are considered as members of families, little effort is made to explain trends in modern terms within the chapters on elements. An explanation of the oxidizing powers of $\mathrm{Mv}$ in the order $\mathrm{Bi}>\mathrm{N}>\mathrm{Sb}>\mathrm{As}>\mathrm{P}$ would be interesting and instructive. The stability of $\mathrm{Pb} I I$ caused by the tightness of binding of the $s$ electrons is hardly consistent with low ionization and promotion energies. Most of these chapters have a decidedly oldfashioned look about them except for the inclusion of ligand field theory and the magnetic and spcetroseopic properties of the transition elements.

Organic chemistry is described as a "complex blend of a systematic organization of information, a vast body of facts and an emerging and exciting theory". Most teachers will accept the treatment according to functional groups and reaction types but a vast body of facts still predominates and 100 pages of organic chemistry pass before a serious look at the theory is taken. The descriptions of polymers and natural products are good (and interesting), however, and the final chapter on the chemistry of living cells will be the highlight of the book for many.

Bonding and molecular structure are well handled as are energy and the states of matter, particularly the solid state. There is an excellent, painless introduction to chemical thermodynamics and a lucid discussion of reaction kinetics. The source and application of infrared spectra are also well treated.

The book could be read by most A-level students and by first year undergraduates. It will be useful to teachers in view of the recent additions to the A-level syllabus. It does not fit naturally with any British course, but, with the assumption of no previous knowledge, it will be useful for late-starters in chemistry.

E. SHERWIN

\section{ANOTHER LOOK ROUND}

\section{Current Developments in Physics}

Edited by Richard Sullivan. Pp. vii + 104. (Bath University Press: Bath, 1968.) n.p.

THIs volume covers the substance of twelve lectures delivered in the University of Bath in the autumn of 1966. It is well produced (although the first diagram appears to contain an error), and covers a course originally intended for people teaching physics in schools and technical colleges. The course has clearly been an interesting and stimulating one, but by its very nature wide ranging, and it is not clear that there is any particular reason, at a time when courses of this sort are becoming by no means uncommon, for proceeding to the stage of publication.

The result is uneven: two or three articles are from the pens of those who never write, even briefly, without being thought-provoking. Others are no more than summaries of something that must have been far more worthwhile, but from which only what is generally familiar remains or, alternatively, something intelligible to the expert alone. The book will certainly be of value for reference to those who attended the course, but their position is very different from that of the general reader: it is hard to envisage the circumstances under which the latter ought to be encouraged to do his reading from such a collection.

\section{RULES FOR BREAKAGE}

\section{Fracture}

An Advanced Treatise. Vol. 2: Mathematical Fundamentals. Edited by H. Liebowitz. Pp. xvi+759. (Academic Press: New York and London, January 1969.) $326 s 8 d$.

THIs volume, the second in a set of seven, comprising an advanced treatise (under the editorship of Harold Liebowitz) on brittle and other types of fracture, is concerned with the mathematical fundamentals of the subject. It is in seven chapters by eight authors all living in the United States and actively engaged in research in this field. The result is an impressive and authoritative account of the subject.

In the first chapter, J. N. Goodier discussed a series of mathematical models for the equilibrium crack including one by the author and M. Kanninen which incorporates the essential non-linearity of the physical field at the tip of the crack.

In chapter two, G. C. Shih and Liebowitz discuss the theories of brittle fracture based on two types of criterion -those of local-stress and energy. They give a detailed account of the calculation of the strain energy, and its consequences for the fracture criteria, for systems of cracks in two and three dimensions with various geometric features and types of loading.

The third chapter, "Mathematical Analysis in the Mechanics of Fracture" by J. R. Rice, suffers from having a title which suggests a wider range of topics than it actually contains. It is, however, a valuable account of the basic background material from the theory of clasticity and of plasticity and of the relevant mathematical tech. niques. It also presents a number of original results based on energy comparisons and the corresponding pathindependent energy line integral with the development of which Rice has been so closely associated.

Chapter four is an account of the theory of the initial yielding of isotropic and anisotropic ductile metals in terms of the macroscopic stress states. The relevant experimental results are reviewed in some dotail and there is a good appendix on the topies from stress analysis the understanding of which is essential for the study of this part of the subject.

In the first part of chapter five, F. Erdogan reviews the continuum theories of crack propagation and, in the second, discusses theories of the spreading of fatigue cracks in plates.

In chapter six, A. M. Freundenthal discusses the statistical approach to brittle fracture which grew out of the lack of reproducibility of brittle fracture and its relation to the distribution of defects and stress in specimens.

The final chapter, by A. C. Eringen, is devoted to an account of the recent theory of micropolar elasticity as developed in recent years by the author and his co-workers. The investigation of crack problems within the framework of this theory is still in its early stages, but for that very reason it is valuable for workers in the field of fracture mechanics to have a self-contained clear account of the basic theory.

In a work of this type it is natural that there should be a certain amount of overlap. What is surprising is to find that a high level of exposition is maintained throughout. The references do not always contain all the papers which perhaps they should, but this is a small price to pay for a book that will prove invaluable to a student taking his first steps in the subject and stimulating even to those who have been engaged in research in it for many years. A novel feature is that towards the end of each chapter there is a section entitled "Recommended Research" which identifies the technical problems and the relevant research areas in which effort is required to close the gaps in our understanding of the subject. The total result is a handsome volume which should be possessed by everyone working on the theory of brittle fracture.

TAN N. SNEDDON 